\title{
Penggunaan Berbagai Macam Legum Cover Crop (LCC) Dalam Menyerap Logam-Logam Berat Pada Lahan Bekas Tambang Emas Di Kabupaten Sijunjung
}

\author{
Giska Oktabriana. S'), Riza Syofiani ${ }^{1)}$, Gusmini ${ }^{2)}$, Aprisal ${ }^{2)}$ \\ ${ }^{1)}$ Prodi Agroteknologi, STIPER Sawahlunto Sijunjung \\ 2) Jurusan Ilmu Tanah Universitas Andalas \\ Email : giskaoktabriana@ymail.com
}

The Uses of Various Types of Legum Cover Crops (LCC) in Absorbing of Heavy Metals in Former Gold Mine Fields In Sijunjung Regency

\begin{abstract}
This study has used a variety of Legum Cover Crops (LCC) in an effort to absorb heavy metals on ex-gold mine land in Sijunjung district. The aim of the study was to see the best LCC in absorbing heavy metals on ex-gold mine land. This research was carried out in the Outer Nutmeg Nagari of Koto Tujuh Subdistrict, Sijunjung Regency for 3 months and continued with analysis in the Soil Laboratory of the Faculty of Agriculture, Andalas University. The design used in this study was a $5 \times 3$ randomized block design with 5 treatments and 3 replications, treatment of $L C C$ plant use where, $A=$ control (without $L C C$ ), $B=$ Mucuna conchinchinensis, $C=$ Calopogonium mucunoide, $D=$ Centrocema pubescen, $E=$ Mucuna bracteata. Data analysis using 5\% ANOVA table if $F$ count is more calculated than F table 5\% and BNJ 5\% further test. From the results of these studies it can be concluded that the use of Mucuna bracteata LCC is able to absorb more heavy metals than other types of LCC.
\end{abstract}

Keywords: LCC, heavy metals, ex-gold mine land

\begin{abstract}
ABSTRAK
Penelitian penggunaan berbagai macam Legum Cover Crop (LCC) dalam menyerap logam-logam berat pada lahan bekas tambang emas di kabupaten sijunjung. Tujuan penelitian adalah untuk melihat LCC yang paling bagus dalam menyerap logam-logam berat pada lahan bekas tambang emas. Penelitian ini dilakukan di Nagari Pala Luar Kecamatan Koto Tujuh Kabupaten Sijunjung selama 3 bulan dan dilanjutkan dengan analisis di Laboratorium Tanah Fakultas Pertanian Universitas Andalas. Rancangan yang digunakan dalam penelitian ini adalah Rancangan Acak Kelompok (RAK) 5x3 dengan 5 perlakuan dan 3 ulangan, perlakuan penggunaan tanaman LCC dimana, A=Kontrol (tanpa LCC), B = Mucuna conchinchinensis, $\mathrm{C}=$ Calopogonium mucunoide, $\mathrm{D}=$ Centrocema pubescen, $E=$ Mucuna bracteata . Data analisis dengan menggunakan tabel Anova 5\% apabila $\mathrm{F}$ hitung lebih hitung lebih dari $\mathrm{F}$ tabel $5 \%$ dan uji lanjut BNJ 5\%. Dari hasil penelitian tersebut dapat disimpulkan bahwa penggunaan LCC jenis Mucuna bracteata mampu menyerap logam berat lebih banyak dibandingkan jenis LCC lainnya.
\end{abstract}

Kata Kunci : LCC, Logam-logam berat, lahan bekas tambang 


\section{PENDAHULUAN}

\begin{tabular}{lrrr} 
& \multicolumn{4}{c}{ Sijunjung } & merupakan salah \\
satu Kabupaten & yang & ada di \\
Sumatera & Barat yang & memiliki \\
cadangan & tambang & emas.
\end{tabular} Penambangan emas di Kabupaten Sijunjung dilakukan secara ilegal yaitu tidak dilaporkan kepada pihak atau instansi terkait. Eksplorasi emas bukan hanya dilakukan pada aliran sungai namun merambat ke area persawahan milik masyarakat. Penambangan emas ini tidak lagi dilakukan sebagai pekerjaan sampingan, akan tetapi sudah menjadi usaha utama yang membutuhkan modal yang relatif besar.

Masalah yang dihadapi pada lahan bekas tambang ini adalah rendahnya hasil tanaman dan produktivitas lahan yang disebabkan kurang baiknya sifat fisik dan kimia tanah pada lokasi penambangan emas. Karakteristik tanah yang telah mengalami degradasi diantaranya adalah rendahnya daya pegang air, porositas besar, kesuburan tanah yang rendah seperti tanah masam, $\mathrm{N}$ Total, P-tersedia, kapasitas tukar kation (KTK) tanah dan kandungan basa-basa $(\mathrm{K}, \mathrm{Ca}, \mathrm{Mg}$ dan $\mathrm{Na})$ yang rendah dan juga Al yang terlarut pada tanah sangat tinggi dan juga tingginya kandungan logam berat serta senyawa beracun yang dapat meracuni makhluk hidup.

Berbagai cara yang bisa dilakukan untuk memperbaiki kerusakan yang terjadi akibat penambangan yaitu dengan penggunaan Legum cover crop (LCC) yang mampu hidup pada tanah yang rusak. Tanaman leguminose cover crop ditanam pada reklamasi lahan bekas tambang berguna untuk melindungi tanah dari kerusakan erosi dan tanaman ini mampu tumbuh dan memproduksi bahan organik dalam jumlah besar, akar tanaman leguminose ini dapat memperbaiki sifat fisik dan kimia tanah serta mampu menyerap logamlogam yang bersifat meracun pada tanah akibat dari penambangan.

\section{BAHAN DAN METODE}

Penelitian ini dilakukan di Nagari Pala Luar Kecamatan Koto Tujuh Kabupaten Sijunjung selama 3 bulan dan dilanjutkan dengan analisis di Laboratorium Tanah Fakultas Pertanian Universitas Andalas. Rancangan yang digunakan dalam penelitian ini adalah Rancangan Acak Kelompok (RAK) $5 \times 3$ dengan 5 perlakuan dan 3 ulangan, perlakuan penggunaan tanaman LCC dimana :

$\mathrm{A}=$ Kontrol (tanpa LCC),

$\mathrm{B}=$ Mucuna conchinchinensis,

$\mathrm{C}=$ Calopogonium mucunoide,

$\mathrm{D}=$ Centrocema pubescen,

$\mathrm{E}=$ Mucuna bracteata .

Data analisis dengan menggunakan tabel Anova 5\% apabila $\mathrm{F}$ hitung lebih hitung lebih dari $\mathrm{F}$ tabel $5 \%$ dan uji lanjut BNJ 5\%.

\section{Pelaksanaan penelitian 1.1 Persiapan lahan}

Persiapan lahan dimulai dengan penyiangan lahan tersebut dari gulma yang ada. Setelah penyiangan dilakukan pembuatan petak-petak percobaan dengan ukuran $2 \mathrm{~m} \times 3 \mathrm{~m}$ dengan tinggi 20 $\mathrm{cm}$ dan jarak antar petak $50 \mathrm{~cm}$. 


\subsection{Pengambilan sampel tanah dilapangan}

Pengambilan sampel tanah di lapangan untuk melihat kualitas tanah dilakukan 2 kali yaitu pada tahap pertama (sebelum penanaman

\subsection{Penanaman}

Penanaman tanaman legum cover crop langsung ditanam pada lahan bekas tambang yang sudah dibuat petakan-petakan terlebih dahulu dengan jarak tanam $20 \times 20$ $\mathrm{cm}$.

\subsection{Pemeliharaan}

Pemeliharaan yang dilakukan selama penelitian ini meliputi penyiraman dan penyiangan gulma. Penyiraman dilakukan setiap hari (1 kali sehari) apabila hari tidak hujan. Penyiangan gulma dilakukan dengan cara mencabuti setiap ada gulma yang tumbuh.

\subsection{Panen dan pengambilan sampel tanah}

\section{HASIL DAN PEMBAHASAN}

\subsection{Analisis logam-logam berat tanah (Cd, Hg dan Pb tanah)}

legum cover crop) dan pada tahap kedua dilakukan pada akhir (sesudah panen). Sampel tanah diambil dengan dengan cara komposit pada kedalaman 0-20 cm.

Panen dilakukan pada saat tanaman berumur \pm 3 bulan dan dilakukan pengambilan sampel tanah untuk analisis sifat fisik dan kimia tanah setelah penanaman legum cover crop. Pengambilan sampel tanah sesudah panen dilakukan pada setiap petak perlakuan dengan cara yang sama dengan pengambilan sampel awal.

\section{Pengamatan \\ a. Pengamatan tanah}

Pengamatan tanah meliputi analisis logam-logam berat yang ada pada tanah seperti merkuri, timbal.

\section{b. Pengamatan tanaman}

Pengamatan tanah meliputi serapan logam berat pada LCC seperti $\mathrm{Cd}, \mathrm{Pb}$ dan $\mathrm{Hg}$.

Hasil analisis $\mathrm{Cd}, \mathrm{Hg}$ dan $\mathrm{Pb}$ tanah setelah ditanami LCC dan hasil penelitian dinilai berdasarkan kriteria disajikan pada Tabel 1 .

Tabel 1. Pengaruh penanaman berbagai jenis LCC pada lahan bekas tambang terhadap $\mathrm{Cd}, \mathrm{Hg}$ dan $\mathrm{Pb}$ tanah

\begin{tabular}{cccc}
\hline Perlakuan & \multicolumn{3}{c}{ Sifat dan ciri kimia tanah } \\
\cline { 2 - 4 } & $\begin{array}{c}\mathrm{Cd} \\
(\mathrm{mg} / \mathrm{kg})\end{array}$ & $\begin{array}{c}\mathrm{Hg} \\
(\mathrm{mg} / \mathrm{kg})\end{array}$ & $\begin{array}{c}\mathrm{Pb} \\
(\mathrm{mg} / \mathrm{kg})\end{array}$ \\
\hline $\mathrm{A}$ & $4,05 \mathrm{bk}$ & $0,61 \mathrm{bk}$ & $7,38 \mathrm{bk}$ \\
$\mathrm{B}$ & $2,36 \mathrm{bn}$ & $0,35 \mathrm{bn}$ & $5,52 \mathrm{bn}$ \\
$\mathrm{C}$ & $2,46 \mathrm{bn}$ & $0,41 \mathrm{bn}$ & $5,72 \mathrm{bn}$
\end{tabular}



D
2,72 bn
0,38 bn
5,89 bn
$\mathrm{E}$
$1,24 \mathrm{bn}$
$0,31 \mathrm{bn}$
4,35 bn

Keterangan $:$ bk $=$ batas kritis, $b n=$ batas normal

Dari data pada Tabel 1. dapat dilihat bahwa terdapat penurunan kadar logam berat pada tanah yang setelah mendapat perlakuan penanaman Legum Cover Crop (LCC). Sebelumnya pada analisa awal yang dilakukan terdapat kandungan logam berat dalam tanah pada batas kritis yang dapat ditolreris, akan tetapi setelah dilakukan penanaman LCC logam berat di dalam tanah berada pada kisaran atau kriteria batas normal sehingga tidak bersifat meracun lagi bagi tanaman dan manusia. Tingginya logam berat pada lahan bekas tambang ini mengakibatkan rendahnya hasil tanaman dan produktivitas lahan tersebut. Hal ini sesuai dengan pendapat Subowo et al,. (1999) cit Nopriani (2011) yang menyatakan bahwa adanya logam berat dalam tanah pertanian dapat menurunkan produktivitas pertanian dan kualitas hasil pertanian selain dapat membahayakan kesehatan manusia melalui konsumsi pangan yang dihasilkan dari tanah yang tercemar logam berat tersebut.
Selain itu logam berat juga dapat merusak lingkungan, hewan dan manusia. Menurut Am.geol. Inst, (1976) cit Notohadiprawiro, (2006) logam berat merupakan unsur logam dengan berat molekul yang tinggi, dalam kadar rendah logam berat pada umumnya sudah meracun bagi tumbuhan dan hewan termasuk manusia seperti Timbal $(\mathrm{Pb})$, Tembaga $(\mathrm{Cu})$ dan Cadminum $(\mathrm{Cd})$. Logam berat pada tanah yang ikut terserap oleh tanaman dan berpotensi dikonsumsi oleh manusia, hal ini akan mengakibatkan gangguan terhadap neurologi (susunan syaraf), fungsi ginjal, sistem reproduksi, sistem hemopotik, sistem syaraf, saluran pencernaan, saluran pernafasan, hipertensi dan kerapuhan tulang.

\subsection{Analisis serapan logam berat pada tanaman ( $\mathrm{Cd}, \mathrm{Hg}$ dan $\mathrm{Pb}$ tanaman)}

Hasil analisis serapan $\mathrm{Cd}, \mathrm{Hg}$ dan $\mathrm{Pb}$ tanaman dapat dilihat pada Tabel 2.

Tabel 2. Serapan $\mathrm{Cd}, \mathrm{Hg}$ dan $\mathrm{Pb}$ tanaman

\begin{tabular}{cccc}
\hline Perlakuan & \multicolumn{3}{c}{ Serapan logam berat } \\
\cline { 2 - 4 } & $\begin{array}{c}\mathrm{Cd} \\
(\mathrm{mg} / \mathrm{kg})\end{array}$ & $\begin{array}{c}\mathrm{Hg} \\
(\mathrm{mg} / \mathrm{kg})\end{array}$ & $\begin{array}{c}\mathrm{Pb} \\
(\mathrm{mg} / \mathrm{kg})\end{array}$ \\
\hline $\mathrm{A}$ & - & - & - \\
$\mathrm{B}$ & $36,06 \mathrm{bk}$ & $6,35 \mathrm{bk}$ & $49,11 \mathrm{bn}$ \\
$\mathrm{C}$ & $30,50 \mathrm{bk}$ & $3,65 \mathrm{bk}$ & $41,86 \mathrm{bn}$ \\
$\mathrm{D}$ & $33,29 \mathrm{bk}$ & $4,76 \mathrm{bk}$ & $43,09 \mathrm{bn}$ \\
$\mathrm{E}$ & $46,40 \mathrm{bk}$ & $7,18 \mathrm{bk}$ & $50,35 \mathrm{bn}$ \\
\hline
\end{tabular}


Ket $:$ bk $=$ batas kritis, $b n=$ batas normal

Dari tabel diatas dapat dilihat bahwa tanaman Legum Cover Crop (LCC) mampu menyerap logam berat yang ada didalam tanah bekas tambang emas sampai pada batas kritisnya. Secara kriteria tidak ada perbedaan namun secara angka LCC jenis Mucuna bracteata (E) mampu menyerap logam berat lebih banyak dibandingkan jenis LCC yang lainnya, ini terlihat dalam penyerapan $\mathrm{Cd}, \mathrm{Hg}$ dan $\mathrm{Pb}$. Setiap jenis tumbuhan memiliki respons berbeda terhadap jenis polutan logam berat. Oleh karena itu diperlukan strategi yang tepat untuk memilih jenis fitoremediasi agar mampu memberikan manfaat yang signifikan.

Jenis-jenis tumbuhan untuk reklamasi dipilih terutama dari jenis pionir yang mampu tumbuh dalam kondisi kritis. Pada tahap berikutnya, vegetasi lain akan tumbuh secara alami termasuk jenis-jenis herba yang berpotensi sebagai fitoremediasi. Kriteria jenis tumbuhan fitoremediasi antara lain: memiliki tingkat laju penyerapan unsur dari tanah yang lebih tinggi dibanding tumbuhan lainnya, beradaptasi terhadap unsur polutan yang tinggi pada jaringan akar dan tajuknya, dan memiliki laju translokasi logam berat dari akar ke tajuk yang tinggi sehingga akumulasi polutan lebih besar di bagian atas (Barrow CJ, 1991).

\section{KESIMPULAN DAN SARAN}

\section{Kesimpulan}

Dari penelitian yang telah dilakukan dapat disimpulkan bahwa LCC dengan jenis Mucuna bracteata mampu menyerap logam berat lebih banyak pada lahan bekas tambang emas di Kabupaten Sijunjung.

\section{Saran}

Berdasarkan kesimpulan diatas, maka disarankan untuk menggunakan LCC jenis Mucuna bracteata agar dapat menyerap logam berat pada lahan bekas tambang emas di Kabupaten Sijunjung.

\section{DAFTAR PUSTAKA}

Barrow CJ. 1991. Land Degradation. Cambridge University Press, Great Britain.

Nopriani. L.S. 2011. Teknik Uji Cepat untuk Identifikasi Pencemaran Logam Berat Tanah Di Lahan Apel Batu. Disertasi Pengelolaan Sumber Daya Alam dan Lingkungan. Fakultas Pertanian. Universitas Brawijaya.

Notohadiprawiro. T. 2006. Logam Berat dalam Pertanian. Repro Ilmu tanah Universitas Gadjah Mada 